\title{
Toxicities of Four Parabens and Their Mixtures to Daphnia magna and Alivibrio fischeri
}

\author{
Jaewoong Lee', Seung Hyuck Bang', Yang-Hoon $\mathrm{Kim}^{2+}$, Jiho Min ${ }^{1 *}$ \\ 'Graduate School of Semiconductor and Chemical Engineering, Chonbuk National University, 567 Baekje-daero, deokjin-gu, Jeonju-si, \\ Jeollabuk-do 54896 Republic of Korea; ${ }^{2}$ School of Biological Sciences, Chungbuk National University 1 Chungdae-Ro, Seowon-Gu, Cheongju- \\ si, Chungcheongbuk-do 28644, Republic of Korea
}

\begin{abstract}
The objective of this study was to determine toxicities of four parabens (methyl paraben, MP; ethyl paraben, EP; n-propyl paraben, PP; and n-butyl paraben; BP) and their mixtures to two aquatic microorganisms, Daphnia magna and Aliivibrio fischeri. Parabens are one of the widely used preservatives for personal care products, such as cosmetics, pharmaceuticals and food also. First, each paraben was treated to $D$. magna to measure the toxicity levels as $L C_{20}$ and $L C_{50}$. The results showed their value of MP $(25.2 \mathrm{mg} / \mathrm{L}, 73.4 \mathrm{mg} / \mathrm{L})$, EP $(18.4 \mathrm{mg} / \mathrm{L}, 43.7 \mathrm{mg} / \mathrm{L}), \operatorname{PP}(10.4 \mathrm{mg} / \mathrm{L}, 21.1 \mathrm{mg} / \mathrm{L})$ and $B P(3.3 \mathrm{mg} / \mathrm{L}, 11.2 \mathrm{mg} / \mathrm{L})$. Then, each of the parabens was treated to $A$. fischeri and calculated their $\mathrm{EC}_{20}$ and $\mathrm{EC}_{50}$ by bioluminescence inhibition test. The results showed the values of MP (2.93 mg/L, 16.8 $\mathrm{mg} / \mathrm{L})$, EP $(1.18 \mathrm{mg} / \mathrm{L}, 6.74 \mathrm{mg} / \mathrm{L}), P P(0.51 \mathrm{mg} / \mathrm{L}, 5.85 \mathrm{mg} / \mathrm{L})$ and BP $(0.21 \mathrm{mg} / \mathrm{L}, 2.34 \mathrm{mg} / \mathrm{L})$. These four parabens belong to the group classified as being 'harmful to aquatic organisms' (above $10 \mathrm{mg} / \mathrm{L}$, below $100 \mathrm{mg} / \mathrm{L}$ ). After measuring the toxicity, $\mathrm{EC}_{20}$ values of two or more parabens were tested in order to investigate their toxicity. A total of ten combinations of four parabens were tested. As a result, the bioluminescence inhibition test of $A$. fischeri showed that the toxicity of mixture parabens was stronger than that of a single compound and combinations of three parabens showed the highest bioluminescence inhibition. These results showed that independent toxicity of paraben was maintained. Therefore, it can be predictable that the toxicity of paraben is getting stronger by the addition of other parabens.
\end{abstract}

Keywords: Paraben, Daphnia magna, Aliivibrio fischeri

\section{INTRODUCTION}

Alkyl esters of 4-hydroxybenzoic acid as known as paraben include methyl paraben (MP), ethyl paraben (EP), n-propyl paraben (PP), and n-butyl paraben (BP) are widely used as preservative in personal care products, pharmaceuticals and food [1-3]. Parabens have advantages and disadvantages. Broad spectrum of antimicrobial activity, stability over a wide $\mathrm{pH}$ range, solubility in water are advantages of these [4]. On the other hand, a lot of study have suggested that parabens

Received: April 18, 2018 Accepted: August 21, 2018

Corresponding author: Jiho Min

Graduate School of Semiconductor and Chemical Engineering, Chonbuk National University, 567 Baekje-daero, deokjin-gu, Jeonju-si, Jeollabuk-do 54896 Republic of Korea

E-mail: jihomin@jbnu.ac.kr

Co-Corresponding author: Yang-Hoon Kim

School of Biological Sciences, Chungbuk National University 1 Chungdae-Ro,

Seowon-Gu, Cheongju-si, Chungcheongbuk-do 28644, Republic of Korea

E-mail: kyh@chungbuk.ac.kr

This article is available from: http://e-eht.org/ have estrogen mimic activities in vitro and in vivo for mammalian species, and health aspects of these have been focusing for a long time [5-11].

Normally, MP, PP and their mixture are used in a lot of cosmetics and pharmaceuticals. In European Union (EU) countries and Republic of Korea, PP usage in cosmetic products is allowed to $0.4 \%(\mathrm{w} / \mathrm{w})$ for single ester and $0.8 \%(\mathrm{w} / \mathrm{w})$ for mixtures of all parabens [12]. In Japan, the maximum concentration of $1 \%(w / w)$ parabens are allowed in all cosmetic products [13]. Though some of country in Europe have banned to use it for baby products [14].

Traditionally, aquatic organisms such as crustaceans, fish, and algae are used for aquatic toxicity monitoring [15]. The most popular bioassay used internationally for toxicity screening of chemical compounds and the monitoring of industrial pollutants is certainly the acute toxicity test with freshwater Daphnids such as Daphnia magna and Daphnia pulex [16-22]. In experiments using these organisms, a long exposure time and a large sample volume are required. Such experiments also require difficult skills. Compared to acute toxicity test us- 
ing freshwater daphnids, bioluminescence inhibition test using $A$. fischeri requires shorter exposure time, smaller sample volume, easier skills. In addition, it is more cost-effective. For example, according to the manual, the acute toxicity experiment using daphnia requires 24-48 hours of exposure time to an test volume of $50 \mathrm{~mL}$, but the acute toxicity test using bioluminescent bacteria is carried out with 15 to 30 minutes exposure time to a test volume of $200 \mu \mathrm{L}$ [23]. In this study, these two kinds of acute toxicity tests using D. magna and $A$. fischeri were conducted to determine toxicities of four parabens and their mixtures to aquatic organism and microorganism [15,24-28].

Parabens are released into the environment from the user and factory wastewater. Because of this, parabens and their salts accumulate in water and become water pollutants. In addition, parabens can penetrate human skin easily. They might accumulate in human cellular tissues. Since parabens are used not only as a single component but also as a mixture, activity of paraben mixtures need to be studied. Many studies have reported toxicities of individual parabens. To the best of our knowledge, no studies have reported toxicities of paraben mixtures up to data. Therefore, the objective of this study is to determine toxicities of four parabens (MP, EP, PP, and BP), which are frequently used in cosmetics, pharmaceuticals, and food, and their mixtures to two aquatic microorganisms ( $D$. magna and $A$. fischeri).

\section{MATERIALS AND METHODS}

\section{Chemicals}

The following chemicals were selected for this study: methyl paraben (purity $\geq 99.0 \%$ ) ethyl paraben ( $\geq 99.0 \%$ ), n-propyl paraben $(\geq 99.0 \%)$ and n-butyl paraben $(\geq 99.0 \%)$ were purchased from Sigma-Aldrich (Saint Quentin, Fallaviers, France). These tested chemicals were special-grade reagents and were used without purification. Stock solutions of each paraben were prepared in ethyl alcohol (purity: 99.9\%, Samchun, Korea) for the bioluminescence inhibition test of $A$. fischeri, and in hard reconstituted water (HRW; $0.12 \mathrm{~g} / \mathrm{L} \mathrm{MgSO}_{4}, 0.192 \mathrm{~g} / \mathrm{L}$ $\mathrm{NaHCO}_{3}, 0.008 \mathrm{~g} / \mathrm{L} \mathrm{KCl}, 0.12 \mathrm{~g} / \mathrm{L} \mathrm{CaCO} 3$ in distilled water) for the acute toxicity test of $D$. magna.

\section{Acute toxicity test of $D$. magna}

In this study, D. magna strain was provided by the Korea Institute of Toxicology (Daejeon, Korea). The organism was cultured according to the U.S. Environmental Protection Agency (EPA) 2002 [23]. The culture work was performed in HRW. Culturing was carried out in an incubator at the temperature of $20 \pm 1^{\circ} \mathrm{C}$ and followed a photoperiod application of 16 hours light: 8 hours darkness. Acute toxicity test was performed according to the standard U.S. EPA manual. Each experiment was performed in triplicate with 10 daphnids in a $50 \mathrm{~mL}$ test volume. All the daphnids spent a hour of starvation before treating. To determine the lethal endpoint on D. magna after treating with toxic chemicals, all daphnids were exposed without any feeding until result was checked. After 24 hours, $D$. magna was counted to calculate the average mortality percentage of each chemical concentration. Then, $\mathrm{LC}_{20}$ and $\mathrm{LC}_{50}$ values at which the mortality is $20 \%$ and $50 \%$ were determined from regression curves, showing the relationship between the chemicals' concentrations (mg/L) and mortality of D. magna.

\section{The Inhibition of Bioluminescence of $A$. fischeri}

Luria-Bertani salt medium (LBS; $1 \%$ tryptone, $0.5 \%$ yeast extract, $2 \% \mathrm{NaCl}, 0.3 \%$ glycerol in $50 \mathrm{mM}$ Tris-Cl, $\mathrm{pH} 7.5$ ) was used for A. fischeri culture. A. fischeri strains were grown at 180 rpm and $30^{\circ} \mathrm{C}$ until OD600 reached 0.6-0.7. After that, bioluminescence was confirmed over 1 second integration time. All bioluminescence inhibition tests were carried out in white 96well plate. $2 \mu \mathrm{L}$ of paraben in ethanol and $198 \mu \mathrm{L}$ of $A$. fischeri were transferred into each well, then $200 \mu \mathrm{L}$ reactants (each concentration of four kinds of parabens in LBS) were treated in each well. $2 \mu \mathrm{L}$ of ethanol was set as a zero point. Also, each sample was performed in triplicate. The bioluminescence of $A$. fischeri inhibition was observed in the presence of paraben was measured after different time duration (15 minutes). The bioluminescence was measured by GloMax ${ }^{\circledR}$ Explorer System (Model GM3500; Promega Corp., Madison, WI, USA). A regression curve showing the relationship between each paraben's concentrations and bioluminescence inhibition of $A$. fischeri was used to calculate $20 \%$ and $50 \%$ effective concentrations $\left(\mathrm{EC}_{20}, \mathrm{EC}_{50}\right)$ for inhibiting bioluminescence of $A$. fischeri. Relative bioluminescence inhibition rates were calculated using the following equation:

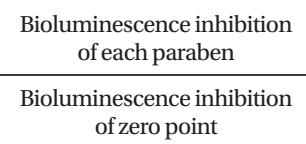

Investigation of Paraben Mixture Toxicity using A. fischeri In this part, the bioluminescence inhibition of paraben mixtures was conducted and calculated by the same method as for the bioluminescence inhibition test of $A$. fischeri. A total of ten combinations of paraben mixtures were examined; $\mathrm{MP}+\mathrm{EP}, \mathrm{MP}+\mathrm{PP}, \mathrm{MP}+\mathrm{BP}, \mathrm{EP}+\mathrm{PP}, \mathrm{EP}+\mathrm{BP}, \mathrm{PP}+\mathrm{BP}, \mathrm{MP}+\mathrm{EP}+\mathrm{PP}$, $\mathrm{MP}+\mathrm{EP}+\mathrm{BP}, \mathrm{EP}+\mathrm{PP}+\mathrm{BP}$, and $\mathrm{MP}+\mathrm{EP}+\mathrm{PP}+\mathrm{BP}$. The $\mathrm{EC}_{20}$ value, which did not significantly affect the treatment concentration, was used in mixture $[29,30]$. 


\section{RESULTS}

$\mathrm{LC}_{50}$ and $\mathrm{EC}_{50}$ are different concepts. The $\mathrm{LC}_{50}$ value entails the kills of $50 \%$ population of D. magna. However, $\mathrm{EC}_{50}$ value does not mean killing $A$. fischeri. To demonstrate this, we confirmed that the growth of $A$. fischeri was inhibited in the $\mathrm{EC}_{50}$ concentration in the bioluminescence inhibition test However, the difference was not $50 \%$. There was just a slight difference (data not shown).

Acute toxicity tests were conducted using D. magna. The treatment concentration of parabens was from 0 to $300 \mathrm{ppm}$, which was a range that unaffected and $100 \%$ affected, and minimum 10 points of concentration were measured. As shown in Figure 1, the slope has increased sharply as alkyl
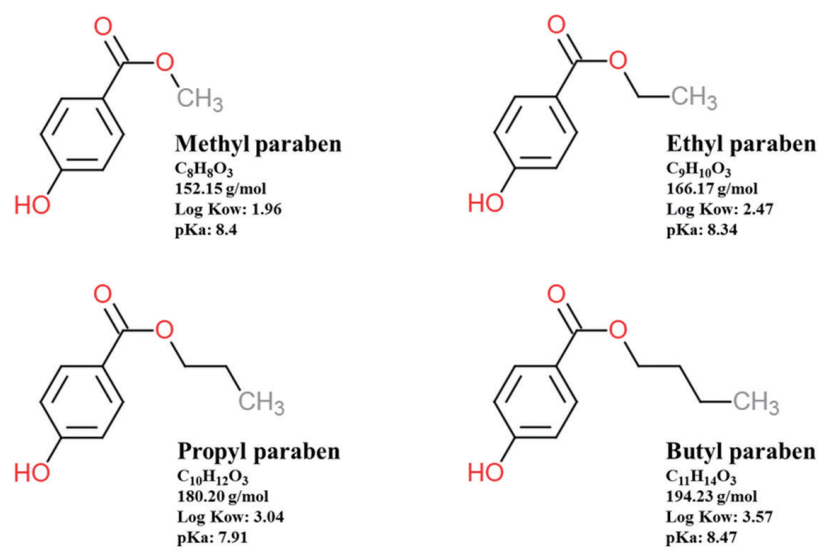

Figure 1. Structure of MP, methyl paraben; EP, ethyl paraben; PP, n-propyl paraben; and $\mathrm{BP}$, n-butyl paraben and their properties.

Table 1. Toxicity parameters obtained using D. magna and $A$. fischeri, expressed as $20 \%$ lethal concentration ( $\mathrm{LC}_{20}$; $\left.\mathrm{mg} / \mathrm{L}\right), 50 \%$ lethal concentration ( $\mathrm{LC} \mathrm{C}_{50}$; $\mathrm{mg} / \mathrm{L}), 20 \%$ bioluminescence inhibition ( $\left.\mathrm{EC}_{20} ; \mathrm{mg} / \mathrm{L}\right)$ and $50 \%$ bioluminescence inhibition ( $\left.\mathrm{EC}_{50} ; \mathrm{mg} / \mathrm{L}\right)$

\begin{tabular}{|c|c|c|c|c|c|c|c|c|}
\hline & \multicolumn{4}{|c|}{ D.magna } & \multicolumn{4}{|c|}{ A. fischeri } \\
\hline & $\mathrm{MP}$ & EP & PP & $\mathrm{BP}$ & $\mathrm{MP}$ & EP & PP & $\mathrm{BP}$ \\
\hline $\mathrm{LC}_{20}(\mathrm{mg} / \mathrm{L})$ & 25.2 & 18.4 & 10.3 & 3.3 & - & - & - & - \\
\hline LC 50 (mg/L) & 73.4 & 43.7 & 21.1 & 11.2 & - & - & - & - \\
\hline $\mathrm{EC}_{20}(\mathrm{mg} / \mathrm{L})$ & - & - & - & - & 2.93 & 1.18 & 0.51 & 0.21 \\
\hline $\mathrm{EC}_{50}(\mathrm{mg} / \mathrm{L})$ & - & - & - & - & 16.80 & 6.74 & 5.85 & 2.34 \\
\hline
\end{tabular}
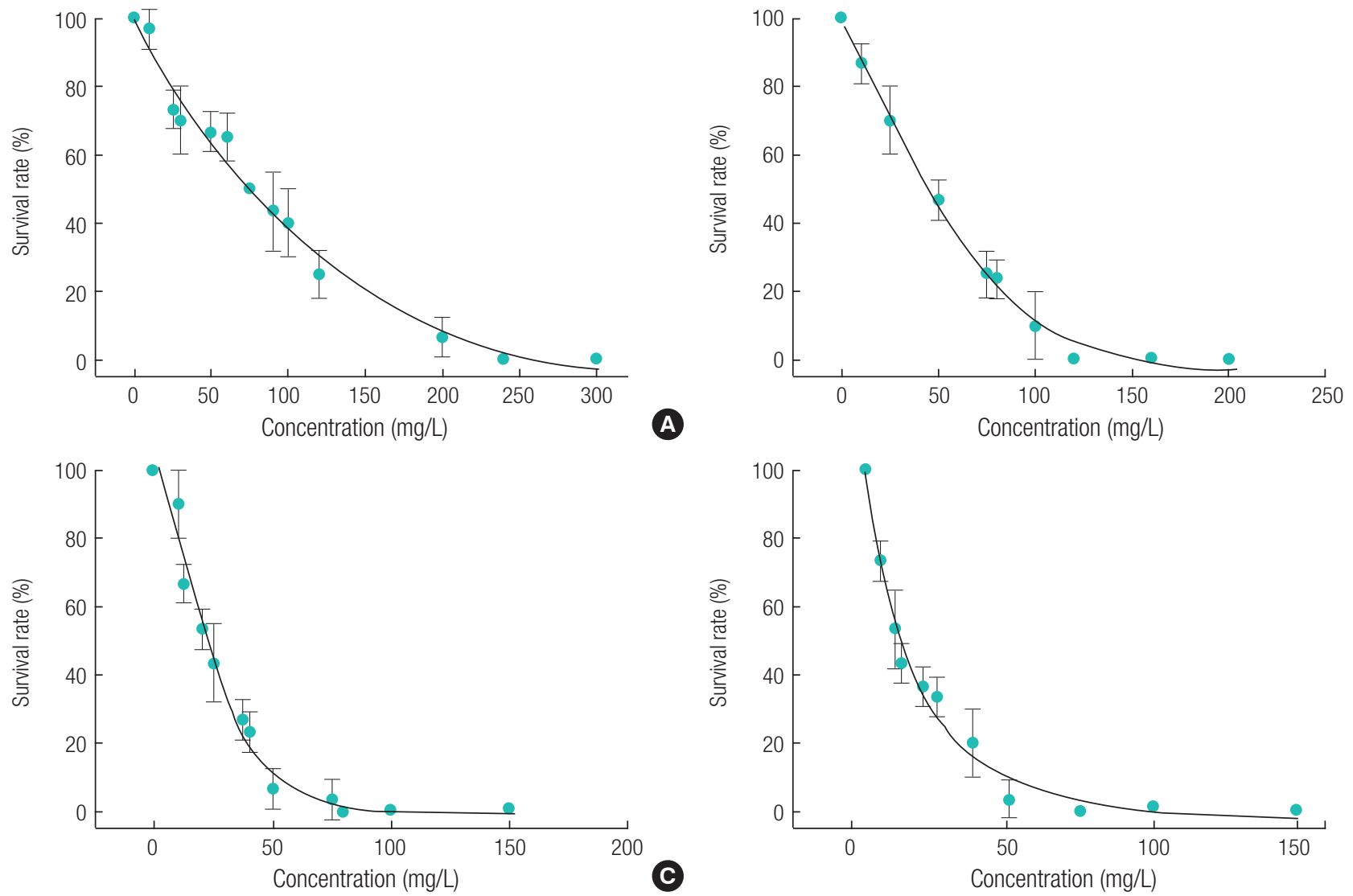

B

Figure 2. Graph of Acute toxicity to D. magna of: (A) methyl paraben, (B) ethyl paraben, (C) n-propyl paraben, and (D) n-butyl paraben. Survival rate was calculated by counting the number of deaths of $D$. magna. 

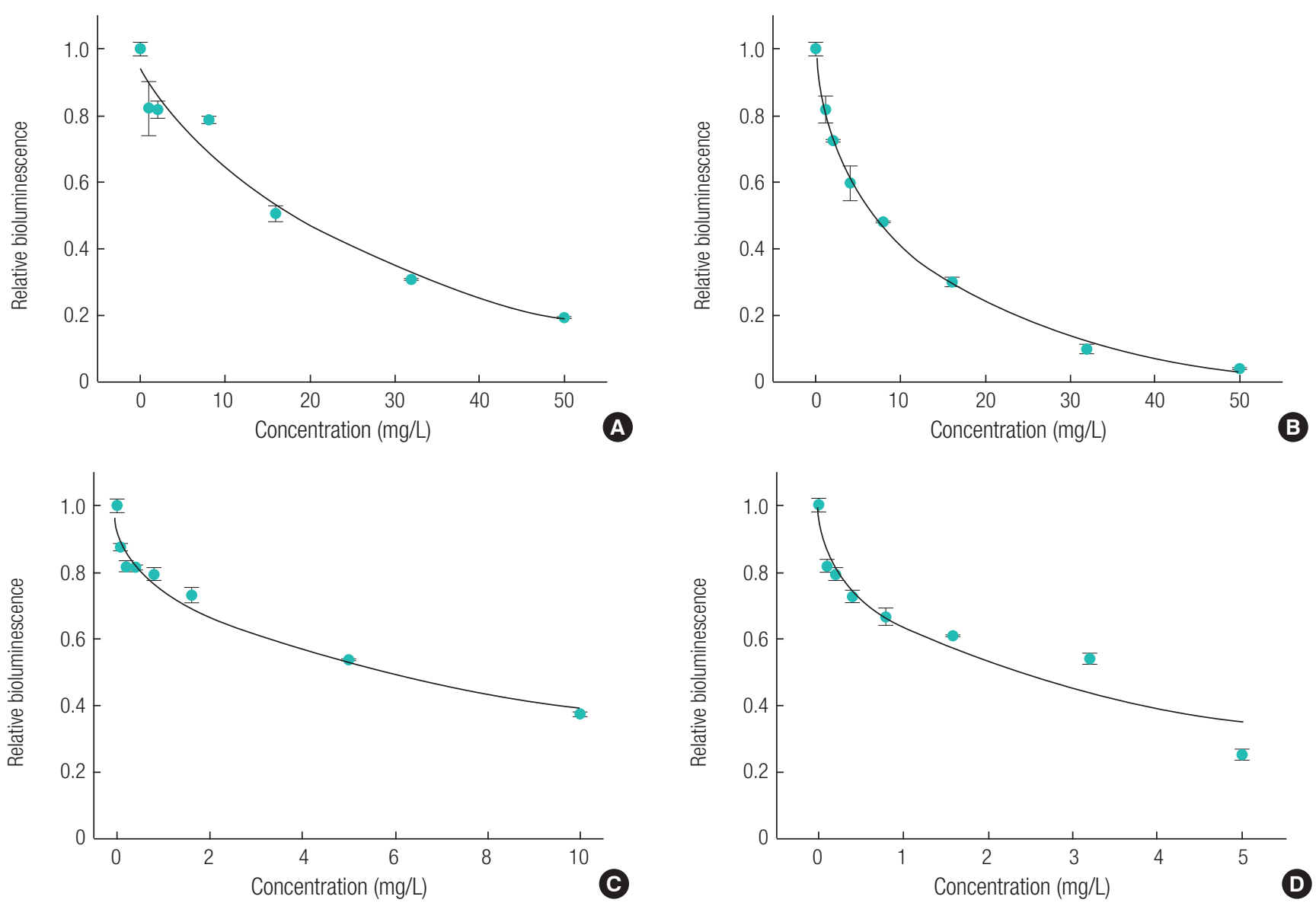

Figure 3. Graph of Acute toxicity to A. fischeri of: (A) methyl paraben, (B) ethyl paraben, (C) n-propyl paraben, and (D) n-butyl paraben.

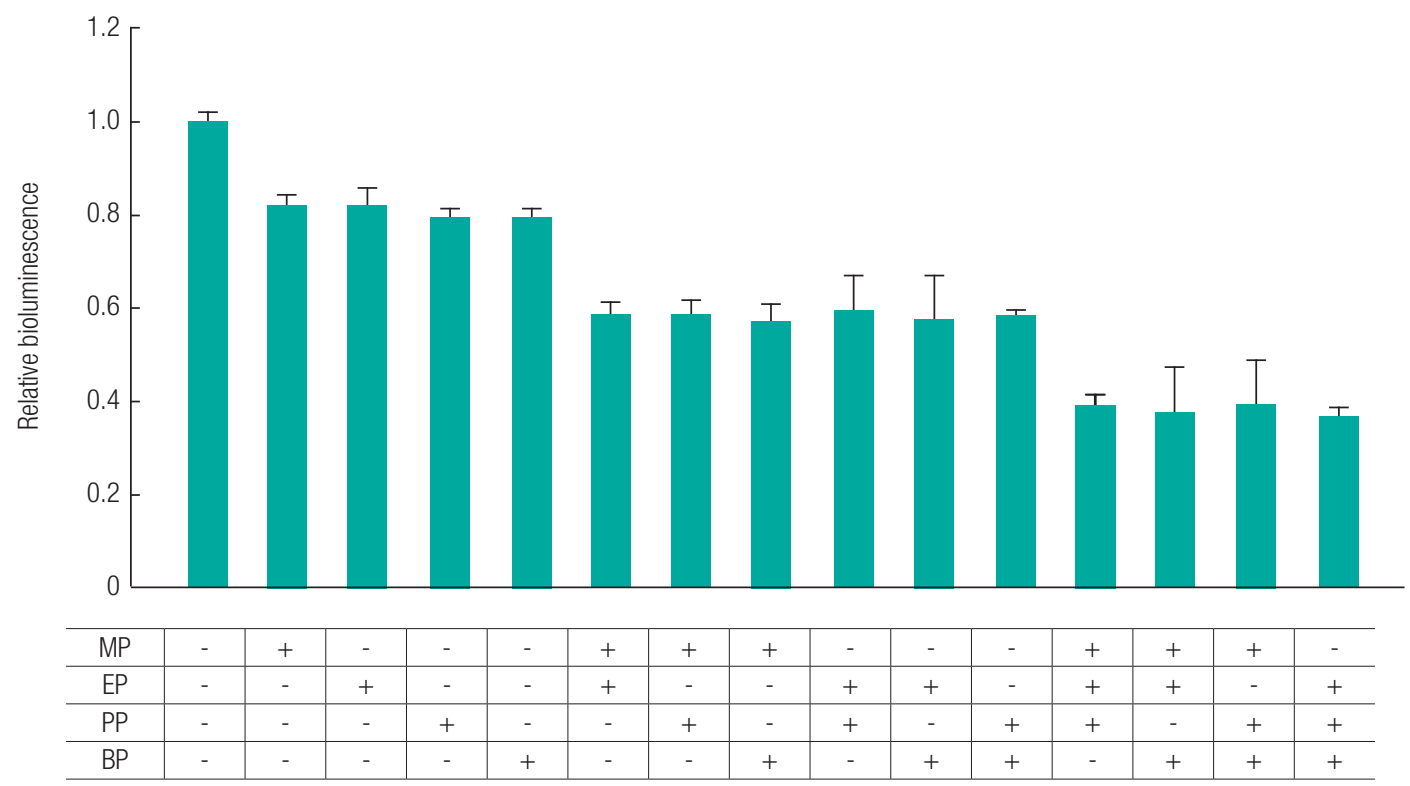

Figure 4. Acute toxicity of paraben mixture to A. fischeri ([+]: present in mixture, [-]: absent in mixture). MP, methyl paraben; EP, ethyl paraben; PP, n-propyl paraben; and BP, n-butyl paraben.

chain length becomes longer. Therefore, the result shows the length of alkyl chain and the strength of toxicity has positive relationship. The calculated $\mathrm{LC}_{50}$ value for $D$. magna of para- bens ranged from $11.2 \mathrm{mg} / \mathrm{L}$ to $73.4 \mathrm{mg} / \mathrm{L}$ (Table 1 ). The toxicity of BP was around seven and two times stronger than that of MP and PP, respectively. 
Bioluminescence inhibition test was conducted using $A$. fischeri. Acute toxicity test of each paraben was performed before the complex effects were examined. The treatment concentration of paraben was from 0 to $50 \mathrm{ppm}$, which was a range that unaffected and $100 \%$ affected, and minimum 8 points of concentration were measured. As shown in Figure 2, relative bioluminescence inhibition rates increase rapidly when alkyl chain gets longer, which has the same tendency as in the acute toxicity test of $D$. magna. The calculated $\mathrm{EC}_{50} \mathrm{val}-$ ue for $A$. fischeri of parabens ranged from $2.34 \mathrm{mg} / \mathrm{L}$ to 16.8 $\mathrm{mg} / \mathrm{L}$ (Table 1). The toxicity of BP is around seven and two times stronger than that of MP and PP.

To investigate the complex effects of paraben mixtures in $\mathrm{EC}_{20}$ value were calculated from the individual results. The calculated $\mathrm{EC}_{20}$ values were ranged from $0.21 \mathrm{mg} / \mathrm{L}$ to $2.93 \mathrm{mg} / \mathrm{L}$ (Table 1). Individual toxicity of parabens was maintained in mixture toxicity (Figure 3). For example, acute toxicity of MP $(2.93 \mathrm{mg} /$ $\left.\mathrm{L}: \mathrm{EC}_{20}\right)$ and PP (0.51 mg/L: $\left.\mathrm{EC}_{20}\right)$ mixture inhibited the intensity of bioluminescence of $A$. fischeri by $40 \%$ (Figure 4 ). As a result, toxicity was got increased by adding compounds.

\section{DISCUSSION}

Parabens are used extensively in personal care products, pharmaceuticals and food, and there are several products that use multiple ingredients rather than one. Therefore, it is very likely that various parabens will coexist in the water or in the user's body. Some studies have been reported that multiple parabens are detected in parts of the body. It is known that the compound is considered to be harmful to aquatic organisms when its $\mathrm{LC}_{50}$ value is greater than $10 \mathrm{mg} / \mathrm{L}$ and less than 100 $\mathrm{mg} / \mathrm{L}[31]$. Acute toxicity tests with $D$. magna showed that the $\mathrm{LC}_{50}$ values of four parabens were $11.4 \mathrm{mg} / \mathrm{L}$ to $73.4 \mathrm{mg} / \mathrm{L}$, and therefore these parabens could be classified to be harmful to aquatic organisms.

Moreover, the toxicity of each paraben was observed to be stronger as the alkyl chain becomes longer. According to the previous studies, one of the most important factor in determining the toxicity of the parabens is the length of alkyl chain and its solubility [30-35]. As the alkyl chain of paraben becomes longer, the solubility decreases, while the toxicity increases [32-37]. Combined with the results in this study, the length of the alkyl chain and solubility of chemicals result in the increase of the acute toxicity.

Toxicities of parabens to A. fischeri appeared to be higher than those to D. magna. However, this value appeared to be higher than value of $A$. fischeri, but this is an error in $\mathrm{EC}$ and $\mathrm{LC}$ interpretation. The $\mathrm{LC}_{50}$ value entails the kills of $50 \%$ popu- lation of $D$. magna. However, A. fischeri was hardly affected by growth (data not shown) and only inhibited bioluminescent at concentration of $\mathrm{EC}_{50}$. This can be interpreted that D. magna was affected more sensitive to paraben toxicity than $A$. fischeri.

As a result of an experiment that the $\mathrm{EC}_{20}$ value of two or more parabens was mixed and treated to $A$. fischeri, and the inhibition of the bioluminescence was measured to calculate the acute toxicity. all mixtures inhibited bioluminescence by approximately $40 \%$, which indicates mechanism of addition toxicity in mixture parabens. It showed that treatment with twice the $\mathrm{EC}_{20}$ value of a single component inhibited $30 \%$, whereas all mixture has shown higher inhibition that about $10 \%$ than single component. As a result, paraben mixture is more toxic in products. Mixtures of MP and PP, which are mainly used in numerous products, showed the same tendency with others.

Mixture of parabens is effective as preservative, while is toxic to aquatic organisms. It is important to determine toxicity of mixture using D. magna, as a higher organism in animals. Moreover, it must determine toxicity of mixture using human cells because all parabens were detected in human body recently. Toxicity of mixtures should be investigated until proper alternative preservative is developed $[38,39]$.

\section{ACKNOWLEDGMENT}

This work was carried out with the support of "Cooperative Research Program for Agriculture Science and Technology Development (Project No: PJ01267701)" Rural Development Administration, Republic of Korea.

\section{REFERENCES}

1. Cashman AL, Warshaw EM. Parabens: a review of epidemiology, structure, allergenicity, and hormonal properties. Dermatitis 2005;16(2):57-66.

2. Janjua NR, Mortensen GK, Andersson AM, Kongshoj B, Skakkebæk NE, Wulf HC. Systemic uptake of diethyl phthalate, dibutyl phthalate, and butyl paraben following whole-body topical application and reproductive and thyroid hormone levels in humans. Environ Sci Technol 2007;41(15):5564-5570.

3. Núñez L, Tadeo J, García-Valcárcel A, Turiel E. Determination of parabens in environmental solid samples by ultrasonic-assisted extraction and liquid chromatography with triple quadrupole mass spectrometry. J Chromatogr A 2008;1214(1-2):178-182.

4. Soni M, Burdock G, Taylor S, Greenberg N. Safety assessment of propyl paraben: a review of the published literature. Food Chem Toxicol 2001;39(6):513-532.

5. Terasaki M, Makino M. Determination of chlorinated by-products of parabens in swimming pool water. Int J Environ Anal Chem 2008;88(13) 911-922.

6. Albero B, Pérez RA, Sánchez-Brunete C, Tadeo JL. Occurrence and 
analysis of parabens in municipal sewage sludge from wastewater treatment plants in Madrid (Spain). J Hazard Mater 2012;239-240:48-55.

7. Błędzka D, Gromadzińska J, Wąsowicz W. Parabens. From environmental studies to human health. Environ Int 2014;67:27-42.

8. Byford J, Shaw L, Drew M, Pope G, Sauer M, Darbre P. Oestrogenic activity of parabens in MCF7 human breast cancer cells. J Steroid Biochem Mol Biol 2002;80(1):49-60.

9. Canosa P, Rodríguez I, Rubí E, Bollaín M, Cela R. Optimisation of a solid-phase microextraction method for the determination of parabens in water samples at the low ng per litre level. J Chromatogr A 2006;1124(12):3-10.

10. Harvey PW. Parabens, oestrogenicity, underarm cosmetics and breast cancer: a perspective on a hypothesis. J Appl Toxicol 2003;23(5):285-288.

11. Okubo T, Yokoyama Y, Kano K, Kano I. ER-dependent estrogenic activity of parabens assessed by proliferation of human breast cancer MCF-7 cells and expression of ER $\alpha$ and PR. Food Chem Toxicol 2001;39(12):1225-1232.

12. Buzek J, Ask B. Regulation (EC) No 1223/2009 of the European Parliament and of the Council of 30 November 2009 on cosmetic products. Official Journal of the European Union 2009;L342:59-209.

13. Terasaki M, Abe R, Makino M, Tatarazako N. Chronic toxicity of parabens and their chlorinated by-products in Ceriodaphnia dubia. Environ Toxicol 2015;30(6):664-673.

14. de Schamphelaere KA, Janssen CR. A biotic ligand model predicting acute copper toxicity for Daphnia magna: the effects of calcium, magnesium, sodium, potassium, and $\mathrm{pH}$. Environmental science \& technology 2002;36(1):48-54.

15. Parvez S, Venkataraman C, Mukherji S. A review on advantages of implementing luminescence inhibition test (Vibrio fischeri) for acute toxicity prediction of chemicals. Environ Int 2006;32(2):265-268.

16. Persoone G, Wadhia K. Comparison between Toxkit microbiotests and standard tests. Ecotoxicological Characterization of Waste: Springer; 2009, p. 213-220.

17. de Schamphelaere KA, Janssen CR. A biotic ligand model predicting acute copper toxicity for Daphnia magna: the effects of calcium, magnesium, sodium, potassium, and pH. Environ Sci Technol 2002;36(1):48-54.

18. Deneer J, Sinnige T, Seinen W, Hermens J. The joint acute toxicity to Daphnia magna of industrial organic chemicals at low concentrations. Aquat Toxicol 1988;12(1):33-38.

19. Heijerick DG, De Schamphelaere KA, Janssen CR. Predicting acute zinc toxicity for Daphnia magna as a function of key water chemistry characteristics: development and validation of a biotic ligand model. Environ Toxicol Chem 2002;21(6):1309-1315.

20. Hermens J, Canton H, Janssen P, De Jong R. Quantitative structure-activity relationships and toxicity studies of mixtures of chemicals with anaesthetic potency: acute lethal and sublethal toxicity to Daphnia magna. Aquat Toxicol 1984;5(2):143-154.

21. LeBlanc GA. Acute toxicity of priority pollutants to water flea (Daphnia magna). Bull Environ Contam Toxicol 1980;24(1):684-691.

22. Santore RC, Di Toro DM, Paquin PR, Allen HE, Meyer JS. Biotic ligand model of the acute toxicity of metals. 2 . Application to acute copper toxicity in freshwater fish and Daphnia. Environ Toxicol Chem 2001; 20(10):2397-2402.

23. Weber CI. Methods for measuring the acute toxicity of effluents and receiving waters to freshwater and marine organisms: Environmental Monitoring Systems Laboratory, Office of Research and Development, US Environmental Protection Agency Cincinnati, Ohio; 1991.
24. Backhaus T, Grimme L. The toxicity of antibiotic agents to the luminescent bacterium Vibrio fischeri. Chemosphere 1999;38(14):3291-3301.

25. Marugán J, Bru D, Pablos C, Catalá M. Comparative evaluation of acute toxicity by Vibrio fischeri and fern spore based bioassays in the followup of toxic chemicals degradation by photocatalysis. J Hazard Mater 2012;213-214:117-122.

26. Reemtsma T, Fiehn O, Jekel M. A modified method for the analysis of organics in industrial wastewater as directed by their toxicity to Vibrio fischeri. Fresenius J Anal Chem 1999;363(8):771-776.

27. Viboud S, Papaiconomou N, Cortesi A, Chatel G, Draye M, Fontvieille D. Correlating the structure and composition of ionic liquids with their toxicity on Vibrio fischeri: a systematic study. J Hazard Mater 2012;215:4048.

28. Wang C, Yediler A, Lienert D, Wang Z, Kettrup A. Toxicity evaluation of reactive dyestuffs, auxiliaries and selected effluents in textile finishing industry to luminescent bacteria Vibrio fischeri. Chemosphere 2002;46(2):339-344.

29. Backhaus T, Scholze M, Grimme L. The single substance and mixture toxicity of quinolones to the bioluminescent bacterium Vibrio fischeri. Aquat Toxicol 2000;49(1-2):49-61.

30. Farré M, Asperger D, Kantiani L, González S, Petrovic M, Barceló D. Assessment of the acute toxicity of triclosan and methyl triclosan in wastewater based on the bioluminescence inhibition of Vibrio fischeri. Anal Bioanal Chem 2008;390(8):1999-2007.

31. Europea UeC. Technical Guidance Document in Support of Commission Directive 93/67/EEC on Risk Assessment for New Notified Substances and Commission Regulation (EC) N. 1488/94 on Risk Assessment for Existing Substances: Office for official publications of the European communities; 1996.

32. Cho CW, Pham TPT, Jeon YC, Vijayaraghavan K, Choe WS, Yun YS. Toxicity of imidazolium salt with anion bromide to a phytoplankton Selenastrum capricornutum: effect of alkyl-chain length. Chemosphere 2007;69(6):1003-1007.

33. Fernandez C, Alonso C, Garcia P, Tarazona J, Carbonell G. Toxicity of linear alkyl benzenes (LABs) to the aquatic crustacean Daphnia magna through waterborne and food chain exposures. Bull Environ Contam Toxicol 2002;68(5):637-643.

34. Garcia M, Campos E, Sanchez-Leal J, Ribosa I. Effect of the alkyl chain length on the anaerobic biodegradability and toxicity of quaternary ammonium based surfactants. Chemosphere 1999;38(15):3473-3483.

35. Kurnia KA, Sintra TE, Neves CM, Shimizu K, Lopes JNC, Gonçalves F, et al. The effect of the cation alkyl chain branching on mutual solubilities with water and toxicities. Phys Chem Chem Phys 2014;16(37):19952-19963.

36. Peng G, Roberts JC. Solubility and toxicity of resin acids. Water Res 2000;34(10):2779-2785.

37. Pouillart P, Douillet O, Scappini B, Gozzini A, Santini V, Grossi A, et al. Regioselective synthesis and biological profiling of butyric and phenylalkylcarboxylic esters derivated from D-mannose and xylitol: influence of alkyl chain length on acute toxicity. Eur J Pharm Sci 1999;7(2):93-106.

38. Barr L, Alamer M, Darbre PD. Measurement of concentrations of four chemical ultraviolet filters in human breast tissue at serial locations across the breast. J Appl Toxicol 2018;38(8):1112-1120.

39. Lillo MA, Nichols C, Perry C, Runke S, Krutilina R, Seagroves TN, et al. Methylparaben stimulates tumor initiating cells in ER+ breast cancer models. J Appl Toxicol 2017;37(4):417-425. 